\title{
Juan Rafael Mora y la Campaña Nacional
}

\author{
Lic. Raúl Aguilar Piedrai, Museo Histórico Cultural Juan Santamaría \\ Recibido: 16/3/2015
}

Aceptado: 19/05/2015

\section{INTRODUCCIÓN}

Se ha cavilado acerca del carácter que tuvo esta campaña en la defensa de la identidad histórica del istmo centroamericano. Sabido es que los enfoques historiográficos se dan desde una perspectiva personal y, también, de acuerdo con el punto de vista tratado según sea el área de interés. Afirma Rousseau (1959) que:

Falta mucho para que los hechos que describe la historia, sean la pintura exacta de cómo sucedieron; pues mudan de forma en la cabeza del historiador, amoldándose por sus intereses y tomando color en sus preocupaciones en el sitio de la escena, para que vea un suceso tal como fue. Todo lo disfraza la ignorancia o la parcialidad. Aun sin alterar un rasgo histórico, con sólo ensanchar o estrechar las circunstancias que a él se refieren, ¡cuántas fases diferentes pueden dársele! Poniendo un objeto mismo en diferentes puntos de vista, apenas parecerá el mismo, y con todo no habrá variado otra cosa que la mirada del espectador. ¿Basta en obsequio de la verdad, contarme un hecho verdadero, si me le hacen ver de distinto modo lo que sucedió?

En términos similares se refiere el filósofo polaco, Adam Schaft (1974) cuando afirma:

Las distintas visiones que los historiadores ofrecen de un solo y único acontecimiento, según pertenezcan a épocas o generaciones diferentes, o, si son contemporáneos, según los distintos sistemas de valores en que se fundan y que son la expresión de los intereses de clases opuestas, de concepciones del mundo divergentes, etc.

Más adelante, este mismo autor también menciona:

Si los historiadores a pesar de los métodos y de las técnicas de investigación perfeccionadas, no solo juzgan e interpretan idénticas cuestiones y acontecimientos en términos diferentes, sino que
Raúl Aguilar Piedra. Juan Rafael Mora y la Campaña Nacional. Revista Comunicación. Año 36, vol. 24, núm. 1. Enero - julio, 2015. Tecnológico de Costa Rica. ISSN Impreso: 0379-3974/ e-ISNN: 1659-3820 
también seleccionan, perciben y presentan de modo distinto los hechos, ipuede afirmarse que estos historiadores ejercen simplemente una propaganda artera en vez de practicar la ciencia? (Schaft, 1974).

Desde luego, lo que aquí se presenta es un punto de vista de cómo se han visto los acontecimientos históricos y cómo se ven en relación con la experiencia de trabajo que se ha tenido. No es un asunto de equivocaciones, sino más bien de opinión que puede ser o no ser compartida. Corresponde al lector tener su propia interpretación de los hechos. Lo que sí parece indispensable es que el profesional en historia y el no profesional, tengan su punto de vista y de que no pase inadvertido el hecho histórico del que se ocupan.

El estudio de la Historia Patria exige un mayor dominio y comprensión del tema. Es necesario enmarcarlo dentro de la realidad local, regional y mundial. Dice en su autobiografía el destacado historiador inglés Eric Hobsbawm (2003):

La historia necesita la distancia (el destacado es del autor), no sólo de las pasiones, las emociones, las ideologías y los miedos de nuestras guerras de religión, sino de las tentaciones todavía más peligrosas de la "identidad". La historia requiere movilidad y la capacidad de investigar y explorar un vasto territorio, esto es, la capacidad de saberse mover más allá de nuestras propias raíces.

Considera Hobsbawm (2003) que la edad permite alguna perspectiva histórica pero que la distancia es esencial para alcanzar una mayor comprensión de los hechos. Al estar próximo el bicentenario del nacimiento de Don Juan Rafael Mora, creo que es suficiente "distancia" para incursionar en los comienzos de la vida republicana costarricense y, por supuesto, en la guerra contra los filibusteros.

Pero esto es una tarea que queda en manos de los investigadores del presente y del futuro. En la actualidad, el acervo documental que conserva el Archivo Nacional referente a Mora y otros temas de interés para la historiografía costarricense es tan valioso como inexplorado. A éste, deben agregarse también los papeles que existen en los archivos de familia. En su conjunto, quedan a la espera de nuevas investigaciones.

\section{DON JUAN RAFAEL MORA}

No hay duda de que Don Juan Rafael Mora es una figura histórica controversial y su gestión administrativa permite ser enfocada de diferentes modos, perspectivas y metodologías; pero lo que no se puede hacer es ignorarlo. Omitir una figura como la de Mora en la Historia Patria, es mutilar el conocimiento que se tiene de nuestro pasado. En el caso de Juan Rafael Mora, por el largo período que se desempeñó como presidente de la República, por el momento histórico en que se desenvolvió y por las repercusiones que tuvo la guerra contra los filibusteros, no puede pasar inadvertido.

Corresponde al lector hacer su propia interpretación de los hechos históricos en relación con la experiencia de trabajo que ha tenido. No es un asunto de equivocaciones sino de criterio u opinión que puede ser o no ser compartida. Desde luego, lo que aquí se presenta es un punto de vista de cómo se ven y se han visto los acontecimientos históricos en relación con la experiencia de trabajo. Tanto el lector profesional como el aficionado, tienen su propia impresión sobre el personaje; lo importante es que no pase inadvertido desde el punto de vista histórico.

Como estadista, don Juan Rafael Mora fue visionario y como patriota, su papel es incuestionable. Desde muy antes de ocupar la Primera Magistratura de la República, se dio a conocer en su afán de servir a la patria.

Hace un tiempo conversábamos con un distinguido historiador académico universitario en torno del papel histórico de Don Juan Rafael Mora y me decía: "Para mí, don Juanito Mora es la Campaña Nacional y se acabó". Ciertamente, este hecho histórico, es el papel por el que se le asocia muy especialmente. Sin embargo, como decía don Tomás Soley Güell (1875-1943), la Campaña Nacional de 1856-1857 es la experiencia histórica que oculta muchas de sus actuaciones y es la que "Perfecciona el alma nacional de la Joven República dotándola de su epopeya histórica y creando su leyenda heroica" (Soley, 1947).

\section{OBRA DE GOBIERNO}

Es un hecho que los factores que inciden en la labor de gobierno durante los comienzos de un régimen republicano son diversos y, por lo tanto, difíciles de juzgar por una sola de las acciones de la administración. Independientemente de la posición que se tenga ante el personaje histórico, son muchas las variables de interpretación existentes y las condiciones que determinan su desenvolvimiento. Pobre contribución se hace con ignorar la labor de un gobernante. Por más simpatía o antipatía que se tenga hacia él, no deja de ser una figura política que guarda un lugar en la historia del país. No 
es lo mismo transmitir conocimientos a bisoños estudiantes de historia que aventurarse a afirmar sobre Juan Rafael Mora de manera tan concluyente como lo hizo mi amigo y colega.

Casi una década en el poder en un momento histórico especial (los comienzos de la república), aunado a la visión de estadista que tenía, hacen que su gestión administrativa sea fructífera. Desde que asumió la Primera Magistratura, Don Juan Rafael Mora impulsó la modernización y el progreso del país, acorde con su condición republicana. Fue en esta Administración que se llevó a cabo una obra de gobierno importante para el desarrollo nacional, tal y como puede observarse en las numerosas leyes aprobadas por el Congreso de la República durante el período en mención (1849-1859).

En agricultura, impulsó la plantación de café, comercializándolo en el exterior, con lo que impulsó a la vez el comercio local. En materia de comunicaciones, avanzó en las mejoras al camino a Limón y Puntarenas, beneficiándose con ello directamente el comercio exterior a lo largo de la costa del Pacífico y, en forma indirecta, el Atlántico y otros lugares. Proliferaron los contratos de construcción y mejoramiento de estas vías y también de otras vías canaleras y de otros tipos.

Estimuló la migración europea para la colonización del país. En cuanto a la industria, dotó al país de una floreciente Fábrica Nacional de Licores. La infraestructura de la ciudad capital se ve modernizada con la construcción de importantes edificios públicos: Universidad de Santo Tomás, Fábrica Nacional de Licores, Hospital San Juan de Dios, Palacio Nacional. También varias comunidades se ven beneficiadas con la construcción de edificios escolares.

Se inaugura el alumbrado público de la ciudad de San José, reglamentándose para esto el cuerpo de serenos. Mejoró el servicio de correos, estableciendo sedes que comunicaban las cuatro cabeceras de las ciudades principales, extendiéndolas a otras del interior.

En materia de instrucción pública, se continuaron los esfuerzos en procura de la enseñanza, dotando a diversas comunidades de edificios escolares y de recursos económicos que hicieron posible el funcionamiento educativo. El establecimiento de un timbre o impuesto, así como lo recaudado por concepto de ventas de tierras cuya renta estaba destinada a la educación, dio lugar a la creación de escuelas de primeras letras. En lo cultural, se inaugura en San José el primer teatro formal.
En beneficencia, se creó en la ciudad capital el hospital San Juan de Dios y el Protomedicato, impulsando el rápido desarrollo del puerto de Puntarenas con el establecimiento de un hospital que atendiera a los vecinos, a los viajeros y al personal de los barcos que navegaban hasta ese lugar.

En cuanto a las relaciones exteriores, vinculó al país con las grandes potencias europeas y la naciente potencia estadounidense. Se reconoce la independencia de los estados centroamericanos, se aprueba el concordato con la Santa Sede y se establece la primera diócesis en Costa Rica, independizando eclesiásticamente al país que dependía hasta ese momento de la diócesis de León, Nicaragua. También se firmó el tratado de límites con Nicaragua Cañas-Jerez, vigente en la actualidad. Además, se firmaron numerosos tratados de paz, comercio y amistad con otras naciones, como también el Tratado de Unión Hispano Americana y la Convención Consular con Chile, entre otros.

Don Juan Rafael Mora careció de formación académica pero era poseedor de gran inteligencia. Amante de la lectura y de las relaciones con intelectuales, además de que tenía condiciones de buen orador. Como mandatario, ejerció su liderazgo comunicándose con el pueblo y con las esferas del Gobierno mediante leyes y decretos, apuntes y notas personales, cartas y misivas, alocuciones y arengas, órdenes y mandatos, declaraciones y partes, discursos y exposiciones; finalmente, las proclamas que son las más divulgadas y mejor conocidas de su gestión de gobernante.

Consciente del momento histórico en que vivía, Don Juan Rafael Mora, como gobernante, dotó a Costa Rica de sólidas instituciones políticas, económicas y sociales que permitieron al país desenvolverse adecuadamente durante los primeros años de la república.

\section{LA CAMPAÑA NACIONAL: SOBRE EL CONCEPTO}

La guerra es una constante en la historia y, por lo tanto, es un viejo legado que heredamos de la humanidad. Bouthoul (1971) explica que como tal:

Está limitada en el tiempo y en el espacio y sometida a unas reglas jurídicas particulares, extremamente variables según los lugares y las épocas (p. 48).

La llegada de William Walker y sus filibusteros a la ciudad de León el 21 de junio de 1855, da origen a un conflicto en el que se involucran todos los países 
de la región centroamericana y que, a la postre, fijarán el límite del expansionismo estadounidense bajo la doctrina del Destino Manifiesto, impulsada por la gran potencia que para entonces consolidaba su territorio mediante la anexión o incorporación de otros.

Se han hecho intentos de dotar esta experiencia bélica centroamericana de una definición precisa y actualizada, de manera que algunos autores han planteado sus propios conceptos, argumentando la obsolescencia, limitación, generalización o falta de relevancia para referirse a este hecho histórico. Tradicionalmente, se ha indicado el concepto integrador de Guerra Nacional de Centroamérica que incluye la participación de los distintos países de la región.

El escritor Armando Vargas Araya, autor del libro más exitoso sobre Don Juan Rafael Mora, suele utilizar el concepto de Guerra Patria con lo que se pretende dimensionar a nivel regional la trascendencia que tuvo este hecho militar para los pueblos del istmo. Korte (2010), basado en un concepto etimológico y militar, considera que "hay una gran confusión respecto de la denominación que debe darse a los acontecimientos político-militares ocurridos" (p. 250).

Aun cuando los diferentes usos terminológicos son enteramente válidos para referirse a este hecho histórico, escasamente riñe con el empleado a nivel local de campaña nacional por medio del que se enfatiza y destaca el carácter peculiar que tuvo para los costarricenses esta guerra contra los filibusteros, en la defensa como nación libre e independiente. Cada país responde por este principio, en cuanto a la magnitud del problema a nivel continental.

Esto no quiere decir que se desvirtúen los esfuerzos hasta ahora alcanzados para precisar este momento histórico. Desde la óptica en que han sido planteados, guardan razón. Es un asunto de acomodo e interés por hacerlo más comprensible, aun cuando se haya cuestionado el término "campaña" o bien se incline por la magnitud y repercusión regional alcanzada. Por la relevancia que tiene el pasado común en el ámbito regional, lo importante del concepto, es que incorpora la participación de todos los países de la región en uno de los momentos históricos en que mayor unión y solidaridad existió en el istmo centroamericano.

En lo personal, mantenemos la decisión de emplear el tradicional concepto de "campaña nacional" para hacer referencia a este momento, en vista de que es uno de los primeros que aparecen en la documentación histórica existente en el Archivo Nacional y, además, no es excluyente del grado de participación y responsabilidad que tuvieron los países centroamericanos. Independientemente de las limitaciones etimológicas, refleja la magnitud que tiene esta guerra en la historia regional; además de que lo hace más comprensible para las generaciones actuales y pasadas.

\section{SITUACIÓN DE CENTROAMÉRICA}

Dotada la América Central de una fisonomía ístmica debido a sus condiciones geográficas y naturales, desde un principio despertó la codicia de las grandes potencias ante la posibilidad de establecer una comunicación que permitiera acortar las rutas comerciales, entre los océanos Atlántico y Pacífico. Nicaragua, con su lago y su río fronterizo, es un caso; Panamá, sin esas condiciones aunque sí con una fisonomía más angosta, es el otro caso de América Central.

Para 1855, la situación política centroamericana era la siguiente: en Guatemala, figuraba como presidente vitalicio el conservador Rafael Carrera Barrios; en El Salvador estaba en el poder José $M^{a}$ San Martín y, en Honduras, José Trinidad Cabañas, ambos liberales. En el caso de Nicaragua, desde el año anterior (1854) se hallaba en plena guerra civil; la rivalidad entre conservadores y liberales los llevó a esta contienda interna y ambas fuerzas, incapaces de inclinar la balanza a su favor, buscaron la manera de imponerse a la facción rival, correspondiéndole a los liberales, con sede en la ciudad de León, contratar los servicios del filibustero Walker para imponerse sobre los conservadores, cuya sede era la ciudad de Granada. En el extremo meridional se halla Costa Rica, presidida en ese momento por Don Juan Rafael Mora, hombre visionario y patriota, quien desde un principio pudo ver con claridad las aspiraciones filibusteras en el vecino país, las que constituían un designio para todo Centroamérica.

El Presidente Mora, con una experiencia centrada más en los asuntos agrícolas y comerciales que en la praxis política, se esmeraba por introducir al país en la ruta del comercio internacional y no por sumarse a la desgastante posición política conservadora o liberal. Debido a este interés prioritario, pudo el gobernante costarricense advertir los inconvenientes de la presencia filibustera en Nicaragua, que solo podían favorecer los intereses estadounidenses en América Central.

La delicada situación política del istmo centroamericano cambiará radicalmente al año siguiente (1856), cuando los liberales ceden su lugar a los conservadores. 
Así, en El Salvador asume el poder Rafael Campo y en Honduras, José Santos Guardiola, facilitando con esto la influencia del gobernante guatemalteco, el conservador Rafael Carrera.

En la historiografía regional se pone en evidencia la manera de pensar y ver los hechos históricos en cada uno de los países. El historiador costarricense Rafael Obregón Loría considera que el gobernante que tenía el país en aquella época, Juan Rafael Mora señaló desde un principio la presencia de Walker y sus filibusteros en Nicaragua como una pérdida de libertad no solo para Costa Rica sino para toda la región ístmica centroamericana. Por esta razón es que Rafael Obregón (1992) menciona:

El plan militar más efectivo de la Campaña Nacional y el que facilitó el triunfo definitivo, fue aquel que desde los inicios de la guerra concibió el presidente Mora, cuál era el de arrebatar a los aventureros la mencionada ruta del Tránsito pues solo así podían ser derrotados y expulsados del territorio centroamericano ( $p$. 113).

La apreciación del médico e historiador nicaragüense Dr. Alejandro Bolaños Geyer (1994), es diferente. Refiriéndose a la iniciativa costarricense para que los países del istmo se enfrentaran conjuntamente al invasor filibustero, señala que:

Las tres repúblicas centroamericanas al norte de Nicaragua reaccionan ante la amenaza de Walker mucho después que Costa Rica. Las distancias y barreras geográficas brindan a Guatemala, El Salvador y Honduras cierta sensación de seguridad que disminuye la urgencia del peligro. Además, ninguna de las tres repúblicas comparte los designios costarricenses sobre la ruta del canal en el río San Juan, por lo que no tienen ese poderoso incentivo para intervenir (p. 30).

Obviamente, librar la guerra contra los filibusteros en 1856-1857 significó para los estados de la región ístmica, un importante desembolso financiero y presupuestario. En realidad, los países situados al norte de Nicaragua, y aun al sur de este país, necesitaban disponer de recursos que permitieran la movilización de los ejércitos. En el caso de Guatemala y de El Salvador, más que tardanza en la reacción, lo que tuvieron que resolver fueron asuntos de financiamiento de sus respectivos ejércitos, ya fuera gravando al pueblo con impuestos o buscando financiamiento en el exterior, en lo cual no siempre estaban de acuerdo los votantes.

En el caso costarricense, fue necesario procurar empréstitos dentro y fuera del país, con los que no solo se cubría la movilización del ejército, sino también la adquisición de implementos de guerra y los alimentos. En verdad que los presupuestos militares dejan de presentarse bajo el ángulo del equilibrio económico interior.

Lo cierto del caso es que predominó el criterio del mandatario costarricense para que los países centroamericanos se unieran y defendieran en común la amenaza que representaba la presencia filibustera en $\mathrm{Ni}$ caragua. Inclusive, refiriéndose a ésta, Pedro Joaquín Chamorro Zelaya, nombrado Prefecto y Subdelegado de Hacienda del Departamento Oriental, Rivas, Nicaragua, decía en una proclama de aquella época, entre otras cosas como menciona Jerónimo Pérez (1928, pp. 142-143): "Dejemos la ignominia a los traidores, a esos hijos ingratos, a los egoístas y a los Estados vecinos por su criminal indiferencia".

Desde luego que esta afirmación en su momento histórico desvirtúa la apreciación que contemporáneamente hace el Dr. Bolaños Geyer (2012). En realidad, el médico nicaragüense, con su afirmación no hace más que acentuar la fragmentación y el localismo característicos de la historiografía centroamericana, porque la condición ístmica es un rasgo de la geografía regional y las razones históricas no pueden estar supeditadas a país alguno.

\section{MODERNIZACIÓN DEL EJÉRCITO}

Durante la Administración Mora, se careció de un Ministerio de Guerra y, menos aún, de un Ministerio de Marina, de modo que todos los asuntos bélicos eran atendidos por el Ministerio de Hacienda, el más importante de todos los ministerios. En un interesante estudio sobre la guerra se afirma Bouthoul (1971):

En todos los Estados organizados, una parte de las rentas nacionales se destina a los armamentos y mantener cierto número de hombres (combatientes, técnicos, obreros de los arsenales y de las fortificaciones, marinos, alumnos de las escuelas militares y navales) que tienen por misión preparar la guerra o mantenerse preparados para poder hacer frente a todo ataque (p. 35). 
Ciertamente, Costa Rica no es la excepción en el siglo XIX y su papel es similar al de los restantes países que fueron colonias durante la dominación española. En este caso, recién adquirida la independencia, el país mantuvo la costumbre colonial de las "milicias". En todo este proceso de modernización juegan un papel especial las milicias, a las que se le brinda especial y constante atención. Como legado colonial continuado durante la república, se diferencian de los soldados permanentes en que estos últimos permanecen acuartelados en las comandancias, además de que cada miliciano recibe una arma que se lleva para su casa, mientras que acude cada domingo a recibir instrucción teórica y manejo del arma recibida, a cargo de un veterano. Por su importancia, las milicias tienen el noble encargo de asegurar la nacionalidad, defender la constitución y mantener la obediencia a las leyes y el respeto a las autoridades legalmente constituidas.

La intención es que el ejército se transformara en momentos de paz y tranquilidad en una especie de guardia nacional que, con instrucción militar, estas milicias, junto con las fuerzas permanentes, constituyan un ejército homogéneo y sin vicios que garantice el orden establecido. Es por esta razón que el Gobierno, interesado en ellas, estimula el espíritu cívico en el marco de las doctrinas republicanas.

La modernización del ejército se inicia con el reemplazo del armamento existente. Para esto se escogió un armamento inglés, similar al empleado en la Guerra de Crimea. De este modo, los almacenes del Estado no solo dispusieron de un nuevo equipo que sustituía el obsoleto fusil de chispa o pedernal, sino que también dispuso de recursos para la adquisición de los nuevos equipos y otros elementos bélicos, así como las municiones y la pólvora necesarias.

El proceso de modernización fue muy importante puesto que incluía no solo la estructuración militar, redacción de códigos, pago de asesorías y otros compromisos financieros, sino que también se destinaban recursos para la sustitución del armamento y demás implementos. De ahí la frecuente confesión de don Manuel José Carazo, ministro de Hacienda, referente a su limitación por desconocimiento de los asuntos militares, pero esto no fue razón suficiente para considerar estos asuntos en el presupuesto nacional. Todo lo contrario, lo militar siempre fue contemplado dentro del proceso de innovación emprendido por la administración Mora.
Una de las principales medidas que se dan al comienzo de la administración Mora, fue la decisión crear en San José un segundo cuartel (el de Artillería) y con esto evitar la excesiva concentración de poder en la figura de un solo comandante, dividiendo el armamento entre ambos cuarteles, con lo que se evitaba y aseguraba la estabilidad política siempre amenazada en la situación anterior; sin embargo, en la Memoria de Hacienda de 1854, el ministro de Hacienda deja entrever la conveniencia de unificar dichos cuarteles pues considera que ya han desaparecido las razones que motivaron este fraccionamiento y propone poner al frente una figura militar, sugiriendo incluso su nombre: el general don José Joaquín Mora, hermano del presidente de la República. El ministro de Hacienda reconoce en este militar el entusiasmo e interés necesario y expone su criterio de que Costa Rica es el único país del continente cuyo ejército se ha organizado sin debilitar el espíritu cívico, tan necesario para inculcar la defensa de las libertades de la nación. Por lo tanto, es un ejército dispuesto a defender con firmeza y patriotismo la libertad y la integridad territorial.

Muy provechoso fue el empleo del prolongado tiempo de paz del país. A diferencia de los demás ejércitos centroamericanos, que se hallaban sumergidos en constantes luchas intestinas, Costa Rica logró la modernización apropiada a las circunstancias de la época, gracias al extenso período de tranquilidad que tuvo.

Comparativamente, el ejército costarricense en la contienda, junto con el guatemalteco, era el mejor equipado y de los más modernos. Esto explica la razón por la que, una vez que se presentaron los filibusteros en Nicaragua, los costarricenses estaban preparados, tanto en los gastos normales en que incurrirían, como también en el adoctrinamiento militar requerido.

Para 1855, en vísperas de la guerra contra los filibusteros, el país contaba con 6650 plazas. En 1856 se expidió la ley que autorizaba su elevación hasta 9000 hombres, sin llegar a utilizar este límite por considerarse innecesario.

\section{MENSAJES Y PROCLAMAS}

Podría pensar que un hombre curtido en la praxis agrícola y comercial presenta alguna limitación a la hora de expresarse. Sin embargo, Don Juan Rafael Mora, con su particular inteligencia, no presenta esta limitación al expresarse de manera coherente a lo largo de toda su gestión administrativa (1849-1859). Esto queda claramente evidenciado en las manifestaciones dirigidas al pueblo 
costarricense y a los órganos del Estado. Los mensajes al Congreso Nacional, los discursos pronunciados en distintas ocasiones, las comunicaciones diversas y las proclamas pronunciadas en distintos momentos $y$, particularmente, durante la guerra contra los filibusteros, le permiten expresarse de manera apropiada, al punto de que su pensamiento guarda una vigencia permanente hasta el presente y esto lo ha llevado a ser considerado como el primer ensayista costarricense.

La importancia de este tema, justifica enteramente su tratamiento independiente y separado del comentario. Como dice Durán Luzio (2010):

Debido a la vehemencia con que suelen actuar sus detractores, no faltará quien diga que los escritos de Don Juan Rafael Mora, no los escribió Juan Rafael Mora, sino alguien más; pero a menos de que haya una prueba irrefutable al respecto, el alegato carece de valor suficiente como para desvirtuar la presunción de su autoría (p. 7).

La manera de expresarse de Don Juan Rafael Mora como gobernante fue realmente notable.

\section{PERIODIZACIÓN}

A mediados del siglo XIX, el mundo occidental experimentó una serie de desafíos y retos que los centroamericanos enfrentaron con la seriedad y responsabilidad del momento histórico vivido. Costa Rica, en asocio con las restantes repúblicas del istmo tuvo que enfrentar la agresión de los filibusteros, debido al carácter ístmico de la región. Estos países que años antes habían alcanzado en forma pacífica la vida independiente, ahora se enfrentaron con las armas en la mano, a la invasión filibustera. Esta agresión evidencia el expansionismo de que estaba imbuido el pueblo estadounidense luego de que en la década de los años 40 del siglo XIX toma forma la doctrina del Destino Manifiesto, pero que estaba latente en ellos desde los tiempos coloniales.

La guerra contra los filibusteros se da en un lapso relativamente corto, aunque muy significativo en el proceso de desarrollo de las identidades centroamericanas y es claramente identificable en la historia nicaragüense: antes y después de la guerra civil de ese país, iniciada en 1854, en donde los conservadores de Granada y los liberales de León, disputan la supremacía del poder.

A nivel centroamericano, las cinco repúblicas se habían iniciado en la vida independiente desde 1821, aunque formando parte de una república federal pero no es sino a finales de la administración del Dr. Castro y comienzos de la de Juan Rafael Mora, que son los gobernantes que inician la vida republicana independiente.

El enfrentamiento contra los filibusteros se da en uno de los momentos históricos más importantes que contribuyen a definir y precisar la identidad histórica centroamericana. Así, se pueden señalar seis momentos estrechamente relacionados con la guerra librada contra los filibusteros.

\section{$1^{\text {a }}$ ETAPA: ANTECEDENTES (1850-1856)}

Aunque en materia de antecedentes se puede ir hasta las primeras actividades filibusteras, en este caso se desea hacer hincapié en las acciones filibusteras que, de algún modo, repercutieron en la diplomacia de la época y tenían que ver con Centroamérica. Por este motivo se insiste en que los países del área tuvieron que llevar a efecto una verdadera batalla diplomática, que tuvo lugar previo a la guerra contra los filibusteros. Una vez que el país agotó todas las posibilidades en materia diplomática, la única opción en defensa de la institucionalidad del país era la guerra. Afirma Picado (2006):

Constituye un importante capítulo de nuestras relaciones con los demás estados centroamericanos, con los Estados Unidos y con algunas naciones europeas. Fue además nuestra política internacional de ese tiempo [del filibusterismo] una excepción al huraño aislamiento que mantiene Costa Rica casi desde sus primeros días. Fue una excepción llena de grandeza y, los hombres que mantuvieron sus resoluciones en el campo de batalla y los que las mantuvieron en nuestras relaciones diplomáticas fueron también, en verdad hombres excepcionales ( $p$. 23).

En esta primera etapa se dan dos fases perfectamente definidas: una en procura de buscar financiamiento y equipo para poder Ilevar a cabo la guerra; la otra, a nivel regional centroamericano, con la finalidad de convencer a las naciones del istmo de que esta era una defensa a la que se tenía que hacer frente en forma conjunta porque estaba en juego el futuro de estas naciones como entidades independientes.

$1^{\text {a }}$ FASE: RELACIONES DIPLOMÁTICAS CON EUROPA, ESTADOS UNIDOS Y AMÉRICA DEL SUR

Aquí se aglutinan las relaciones diplomáticas del país con otras naciones del viejo y del nuevo continente. 
Con Europa, en vista de la debilidad que mostraba el país como república independiente procuró asociarse como protectorado y así asociarse con una potencia mayor que asegurara el respeto a las instituciones establecidas. Aunque era una solución de la época, dichosamente no prosperó entre las potencias a las que se les llegó a proponer. También se procuró la compra de armamento y municiones con algunas potencias europeas lo que se logró gracias a la disponibilidad de países como Inglaterra y Francia. En el caso de los Estados Unidos, ya se perfilaba como una potencia emergente; a pesar de que era en suelo estadounidense donde se organizaban las principales expediciones filibusteras. De acuerdo con lo expresado por el historiador Araya (2006):

La acción diplomática en los Estados Unidos, constituyó el frente más duro y difícil para el gobierno de Costa Rica. Si bien la expedición filibustera no contó con el patrocinio directo del gobierno de Washington, no por ello, las gestiones del representante costarricense en aquella capital dejaron de requerir de una enorme habilidad y esfuerzo. Las acciones diplomáticas costarricenses debieron enfrentarse con un gobierno indiferente y negligente en cuanto a su voluntad de controlar las empresas filibusteras y debieron enfrentar, además, la acción de grupos de interés así como sectores influyentes de la opinión pública estadounidense, abiertamente favorables a las empresas filibusteras y expansionistas (pp. 12-13).

Para el Gobierno costarricense fue muy importante la labor de denuncia que llevaron a cabo sus representantes en Washington, de las que era informado oportunamente, hasta que, a finales de 1855 , en una comunicación dirigida a su superior, el Ministro de Relaciones Exteriores, Joaquín Bernardo Calvo, don Luis Molina (1914, p. 168):

Considero casi imposible que Costa Rica pueda evitar la guerra y conservar sus derechos; $y$ parece preciso que esté preparada a hacer su defensa en el terreno más conveniente.

Con esta advertencia, don Luis Molina se refería a los oídos sordos que prestaban las autoridades estadounidenses a las constantes denuncias que hacían él y sus colegas del istmo centroamericano, referente a las expediciones filibusteras que se organizaban y partían del territorio de los Estados Unidos.
En cuanto a la América del Sur, se realizaron misiones importantes en donde llegaron a calar hondo las vivencias de los países centroamericanos, tan frágiles y expuestos a la invasión filibustera. Precisamente fue aquí donde se intentaron préstamos en dinero que permitieran adquirir el armamento necesario, suministrado por algunas potencias europeas. Con la excepción de Perú que convino un préstamo en dinero para Costa Rica, la labor fue más bien exitosa en lo que respecta a la concientización de la problemática filibustera.

A nivel interno, el país también se esmeró en procurar financiamiento voluntario y gravando también los capitales de la gente económicamente poderosa, para que a modo de préstamos, pudieran financiar en parte el costo de esta guerra.

\section{2. ${ }^{\text {a }}$ FASE CENTROAMÉRICA}

Con Centroamérica, la acción diplomática fue diferente: no fue tanto de denuncia como se había hecho en Estados Unidos, sino más bien de convencimiento de que esta era una guerra en la que se definía la libertad, la independencia y el futuro de las repúblicas del istmo centroamericano y no de un país en particular. El mensaje estaba orientado a convencer a los países del istmo, de que esta era una lucha que debían librar conjuntamente los países de la región ante la amenaza que se cernía sobre Centroamérica. Por supuesto que una decisión de esta naturaleza, afectaba también a los países al norte de Nicaragua.

\section{2. ${ }^{\text {a }}$ ETAPA: PRIMERA CAMPAÑA (MARZO Y ABRIL DE 1856)}

De acuerdo con la historiografía costarricense, la Primera Campaña ocurre cuando el país es invadido por las fuerzas filibusteras y tiene los primeros encuentros bélicos en Santa Rosa y Sardinal. En una segunda fase, los costarricenses intervienen en la Segunda Batalla de Rivas, en el marco de la guerra civil nicaragüense, de modo que, al acudir en defensa del vecino país se daba el ejemplo a las demás naciones del istmo.

En síntesis, esta segunda etapa la constituyen los dos enfrentamientos que tiene el Ejército costarricense en territorio nacional $y$, en una segunda fase, interviene $y$ participa en la Segunda Batalla de Rivas. A partir de este momento, el escenario geográfico de la guerra contra los filibusteros se dará en territorio nicaragüense. 


\section{1. ${ }^{a}$ FASE: BATALLA DE SANTA ROSA (20 DE MARZO DE 1856)}

El primer encuentro bélico entre los costarricenses y los filibusteros, tiene lugar en la Hacienda Santa Rosa, Guanacaste.

En un opúsculo publicado durante la administración de José $M^{a}$ Montealegre en 1860, en el que se pretende justificar las causas por las que se dispuso el derrocamiento de Juan Rafael Mora Porras, Ilega a calificarse de "funesta" la campaña librada contra los filibusteros, diciendo:

El recuerdo de aquella funesta (el destacado es nuestro) campaña aún está vivo entre nosotros. A causa de malas disposiciones del señor Mora y de su hermano D. José Joaquín, quien también mandó en gefe ( $\mathrm{sic}$ ), sufrió el ejército desde el principio, fatigas y privaciones de toda clase. A la victoria de Santa Rosa, debida al valor y dirección de los gefes (sic) subalternos, y manchada por el señor Mora con la fusilación (sic) de veintiún (sic) prisioneros.

¿Por qué calificar de "funesta" la Campaña Nacional? ¿Qué tuvo de "funesta" la Batalla de Santa Rosa? ¿Sí lo que se hizo fue rechazar a quienes habían violado el territorio nacional?

¿Por qué el triunfo de Santa Rosa se debe al valor y dirección de los jefes subalternos si el ejército en esa batalla contó con un Comandante en Jefe que era el general José Joaquín Mora?

¿Qué papel juegan los "jefes subalternos" en la jerarquía militar? ¿Acaso no dependen de un jefe superior o comandante en jefe?

¿Qué puesto desempeñaba el general José Joaquín Mora en el momento de la Batalla de Santa Rosa? ¿En qué se fundamentan para desvirtuar el papel del comandante en jefe que dirigió la batalla?

¿Tiene que ver la defensa del país ante la amenaza con la "fatiga" o "privaciones" de los soldados? ¿Qué tipo de fatiga y privaciones tuvo este ejército?

La Batalla de Santa Rosa es la mayor gloria militar de nuestro ejército, no solo porque fue en defensa del territorio nacional, sino porque fue un triunfo indiscutible para los costarricenses.

Evidentemente, esta pequeña publicación es enteramente subjetiva y poco confiable. Como en este caso, sus inexactitudes y afán de confundir es mayor conforme se avanza en su lectura. Nos parece que todo investigador debe tener cuidado a la hora de emplear testimonios de "memoria histórica", pues estos se pueden acomodar enteramente a un interés específico, sin conocer las circunstancias, interés ideológico y época en que fue escrito, a menos que pueda ser cotejado con otros documentos de valor histórico, confiables y objetivos y así, corroborar lo afirmado por el documento.

Llama la atención en esta publicación el interés en desconocer lo actuado por los hermanos Mora, José Joaquín y Juan Rafael. Aunque algunas afirmaciones pueden tener sentido como argumento, otras son realmente absurdas y carecen de trascendencia a la hora de justificar el golpe de Estado del 14 de agosto de 1859 en contra de Don Juan Rafael Mora, al que se refiere el libro en mención. Pienso, antes de hacer uso de esa fuente de "memoria histórica", debería emplearse la "malicia" característica de todo investigador serio, a fin de cotejar lo que dice la "memoria histórica" con otras fuentes historiográficas que se refieran al mismo tema. A fin de cuentas, lo que persigue todo investigador es alcanzar con su trabajo, el mayor grado de objetividad.

Cuando se afirma que el triunfo de Santa Rosa estuvo manchado por el presidente de la República al fusilar a los filibusteros capturados, se olvida que, escasos tres meses después de ocurrida la batalla, fueron convocados algunos testigos presenciales de los hechos. En esa ocasión se les interrogó acerca de lo actuado por el Presidente Mora. Entre los declarantes estaba el coronel Lorenzo Salazar, quien tuvo a su cargo la fuerza principal que combatió en Santa Rosa y que, también, fue uno de los participantes del golpe de Estado contra Juan Rafael Mora. En la declaración para la cual fue convocado, se le preguntó a Salazar si sabía ¿en qué se fundó el Consejo de Guerra para condenar a muerte a algunos de los filibusteros tomados en la acción de Santa Rosa?. La respuesta de Salazar fue que las leyes de Costa Rica imponen pena de muerte a todos los que alteren el orden público siempre que haya habido efusión de sangre, como sucedió en Santa Rosa.

En esta misma ocasión fueron llamados a declarar también y preguntados sobre otros asuntos, el periodista español José A. Mendoza, el capitán costarricense Miguel Alvarado y el médico alemán, Dr. Carlos Hoffmann.

La acción librada en la hacienda Santa Rosa no solo fue el primer enfrentamiento contra los filibusteros, sino que el triunfo de los costarricenses fue alcanzado 
rápidamente (la batalla tardó solamente 14 minutos). Este encuentro fue suficiente para que el ejército se acreditara el triunfo y obligara al adversario a huir. Fue una victoria suficientemente clara y contundente para poner al descubierto cualquier mito de "invencibles" con el que los filibusteros se hacían acompañar. Permitió al ejército expedicionario costarricense alcanzar el grado de confianza y seguridad necesarias para enfrentar en contiendas ulteriores, a este poderoso enemigo.

\section{COMBATE DE SARDINAL (10 DE ABRIL DE 1856)}

El segundo enfrentamiento con los filibusteros en territorio nacional se llevó a cabo en la desembocadura del Sardinal en el río Sarapiquí; un día antes de llevarse a efecto la gloriosa Segunda Batalla de Rivas.

Aunque los datos y referencias del combate son contradictorios, a final de cuentas fue un enfrentamiento muy importante pues allí los filibusteros estuvieron más próximos al Valle Central costarricense (100 kms). Montúfar (1887), al comentar esta acción, señala:

Las narraciones que hacen Walker y Pérez de la acción de Sardinal, no se encuentran conformes con los partes oficiales que fueron dirigidos al Gobierno de Costa Rica. En aquellos se dice que las tropas de Walker triunfaron y en éstos se asegura que los americanos [estadounidenses] fueron vencidos y que los costarricenses alcanzaron la victoria. Desde luego se observa en la relación de Walker una infidelidad, que se percibe a primera vista: afirma que los costarricenses derrotados no se detuvieron hasta llegar a San José [lo cierto es que el ejército expedicionario costarricense regresó a su base principal situada en Muelle de Sarapiquí] y no San José como afirma Walker en su libro (p. 352).

Desde luego que esta es una de las tantas infidelidades que tiene el libro del filibustero Walker (ya señalaremos otras) por bien escrito que esté, dado lo comprensivo y por el tratamiento integral que le da a esta experiencia del filibusterismo. Los historiadores Bolaños Geyer y Víctor Hugo Acuña así se refieren de este libro. En el caso de la historiografía estadounidense, este libro es muy utilizado para publicar sus asertos y puntos de vista de la experiencia personal del autor. La preparación del libro no deja de tener una intención propagandística y, como toda fuente de memoria histórica, exige ser cotejada con otros documentos de valor histórico.
Para el historiador nicaragüense, Dr. Bolaños Geyer, lo mismo que para la prensa estadounidense de la época, de Sardinal salió triunfante el filibusterismo; no obstante lo consignado en el parte oficial del teniente José Clemente Orozco. Obregón, al referirse a la acción de Sardinal, señala:

Después de una hora de combate, los filibusteros regresaron a La Trinidad y los costarricenses se retiraron hacia el muelle $[s i c] . .$. en verdad los detalles de esta acción no están muy claros ya que los datos consignados tanto por los costarricenses como por los filibusteros, son contradictorios (Obregón, 1992).

\section{2. ${ }^{a}$ FASE: SEGUNDA BATALLA DE RIVAS}

Después de Santa Rosa y Sardinal, el Ejército Expedicionario continuó la campaña interviniendo en la Segunda Batalla de Rivas. A partir de ese momento, el escenario geográfico del enfrentamiento contra los filibusteros fue Nicaragua, donde el interés filibustero era controlar la situación y así ampliar las fronteras de Destino Manifiesto. La Segunda Batalla de Rivas es una de las más sangrientas y prolongadas de esta guerra. Para los costarricenses, Rivas significa la cantera más rica del heroísmo. Fue en esta batalla donde intervino Juan Santamaría, considerado Héroe Nacional costarricense, por cuya participación y el sacrificio de su vida, la tradición lo ha considerado héroe nacional por excelencia; pero, además, fue aquí donde murieron muchos otros nacionales, ya sea como resultado de la batalla que se libró o bien por la aparición de la mortal peste del cholera morbus. A pesar de esto, la Segunda BataIla de Rivas no fue decisiva, por cuanto los filibusteros continuaron afianzándose en el poder en Nicaragua. Para la República de Costa Rica fue en Rivas, donde el ejército expedicionario luchó con denuedo, decisión y sacrificio.

\section{3. ${ }^{a}$ ETAPA: PERÍODO INTERMEDIO (ABRIL-SETIEMBRE 1856)}

¿Por qué intermedio? Desde la óptica de la historiografía costarricense, es un período que está interpuesto entre la primera y la segunda campaña. Ubicado en el marco de la guerra civil nicaragüense, comprende dos fases o sub etapas. Más que bélico, es un período que atiende un aspecto de organización filibustera en $\mathrm{Ni}$ caragua por un lado, aunque le corresponde a Walker presenciar la llegada de las primeras tropas centroamericanas. 


\section{1. ${ }^{\text {a }}$ FASE: WALKER PRESIDENTE DE NICARAGUA (JULIO-SETIEMBRE 1856)}

Aun cuando Walker permanece como presidente de Nicaragua hasta que se rinde ante el comandante Davis de la flota naval estadounidense, el $1 .^{\circ}$ de mayo de 1857, para efectos del Período Intermedio, es una etapa que llega hasta el mes de setiembre de 1856, cuando el conflicto nicaragüense alcanza una nueva dimensión con la participación de todas las fuerzas centroamericanas. Como bien señalamos, más que bélica es una etapa donde los filibusteros se afianzan en el poder en Nicaragua.

La decisión de Fruto Chamorro de reelegirse por dos períodos constitucionales, da comienzo el enfrentamiento entre liberales y conservadores en Nicaragua. El 23 de octubre de 1855, Walker y Ponciano Corral firman un convenio o tratado, mediante el cual se designa presidente a don Patricio Rivas. De acuerdo con este tratado, al estar próximo el vencimiento del período de don Patricio, éste promulga un decreto en el que convoca a nuevas elecciones presidenciales. Participan en estas don Francisco Castellón y don Fruto Chamorro pero el hecho de no haberse efectuado las elecciones en dos departamentos, da lugar a la anulación del proceso efectuado. En vista del problema surgido, don Patricio convoca a nuevas elecciones en las que participan los dos candidatos anteriores pero además, se incluye también a Walker.

En el ínterin de este proceso electoral, cuatro aspectos ocurren que de alguna manera van a repercutir en los acontecimientos siguientes y en la dimensión del conflicto:

a) Ruptura política entre Patricio Rivas y Walker. Rivas, que con anterioridad había declarado la guerra a Costa Rica, ahora entra en desacuerdos con Walker y en procura de mermar la influencia de éste en su gobierno, se traslada de Granada a León $y$, en Chinandega, emite un decreto por medio del cual declara a Walker "traidor".

b) Llegada del patriota cubano Domingo Goicouría. Este patriota en un comienzo contó con el apoyo del filibustero, aunque posteriormente se produce el enfrentamiento entre ambos, convirtiéndose en un controversial adversario de Walker que, a juicio del historiador Obregón Loría, Goicouría dejó una triste memoria en Nicaragua pues fue cruel y sanguinario.

c) Petición de José Trinidad Cabañas. Traído Walker por los liberales de León y expulsado del poder por
José Santos Guardiola, Cabañas solicita a Walker la ayuda necesaria para retomar el poder en Honduras. Al negarse Walker a brindarle el apoyo necesario, no solo provocó dos importantes renuncias en el gabinete de don Patricio Rivas (Máximo Jerez y Buenaventura Selva), sino que desde entonces Cabañas se convierte en un adversario temible, generando la animadversión y la enemistad de este liberal hondureño.

d) Fin de la Guerra Civil nicaragüense. Al deponer las armas los liberales y conservadores el 12 de setiembre de 1856, la guerra librada contra los filibusteros alcanza una nueva dimensión, al regionalizarse el conflicto. Los centroamericanos no van a actuar en el marco de la guerra civil nicaragüense, sino que lucharan por el futuro de la región, conservando y respetando la decisión de los antepasados y haciendo valer el principio de una identidad histórica centroamericana.

Como resultado del proceso electoral, efectuado únicamente en las ciudades de Granada y de Rivas, Walker es electo presidente de la República.

El filibustero, que no estaba satisfecho con Patricio Rivas, le solicita su renuncia, a la cual se opone el señor Rivas hasta que se produce el desconocimiento de Walker, designando en su lugar a don Fermín Ferrer. Seis días después, se produce la ruptura definitiva entre Walker y Rivas, quien se traslada con su gabinete a la ciudad de Chinandega y emite un decreto en el que declara a Walker como traidor, lo mismo que a todos aquellos que por su propia voluntad continúan a su servicio.

Esta fase se inicia con la promulgación del decreto emitido por don Fermín Ferrer en el que reconoce el triunfo de Walker en las elecciones convocadas el $1^{\circ}$ de julio de ese año.

Por otro lado, las fuerzas costarricenses retornan al país y dan lugar a una grave crisis de salud principalmente en el Valle Central al punto de que la población del país se ve drásticamente diezmada. Además, el gobernante costarricense se obligará a atender algunos asuntos de orden político, que impedirán nuevamente liderar a las tropas del país como bien sucedió durante la primera etapa.

\section{REPUBLIC OF NICARAGUA}

MINISTERIO JENERAL [Sic]

Granada, 10 de julio de 1856 
El S. P. E. se ha sabido dictar el decreto que sigue:

Fermín Ferrer Presidente de la República de Nicaragua a sus habitantes.

Habiendo practicado las elecciones del Presidente que debe rejir [sic] los destinos de la nación conforme al decreto fecha diez del mes ppdo; teniendo a la vista los diferentes pliegos de las juntas electorales que han dirigido los pueblos de la república y practicado el escrutinio como corresponde de los candidatos que en ellos aparecen; he tenido a bien decretar y

\section{Decreto}

Art. 1. ${ }^{\circ}$ Declárase electo por mayoría de votos, presidente de la República de Nicaragua al señor Jeneral [sic] D. Guillermo Walker.

Art. 2. ${ }^{\circ}$ Publíquese de una manera solemne y comuníquese al nombrado para que tome posesión de su destino el día doce del mes corriente. Dado en Granada. 10 de julio de 1856. F. Ferrer. Al Sr. Ministro Jeneral [sic] D. Mateo Pineda. Y de suprema orden lo inserto a V. para su debido cumplimiento y publicación, esperando recibo su servidor. PINEDA

Entre las medidas adoptadas por el presidente Walker, están las siguientes: levantamiento de un inventario de las propiedades sujetas a expropiación, las cuales serán entregadas a sus colaboradores más cercanos; declara el idioma inglés como segunda lengua oficial de Nicaragua; anula todos los decretos emitidos con base en la Constitución Federal que incluye precisamente la abolición de la esclavitud, es decir, se instaura nuevamente este tipo de institución, con lo que pretende contar con el apoyo de los sureños estadounidenses.

En lo militar, con la presencia de los ejércitos centroamericanos se anuncia una nueva etapa que es la que pone fin a la guerra civil en Nicaragua, cuando los causantes de esta guerra firman la paz (12 de setiembre de 1856) y la guerra contra los filibusteros alcanza una nueva dimensión: la Guerra Nacional de Centroamérica contra los filibusteros.

Le corresponde a Walker presenciar la llegada de las primeras fuerzas centroamericanas en el mes de julio de 1856. Aunque se llevan a cabo algunos combates, rápidamente las fuerzas centroamericanas requieren de un jefe que coordine las acciones de los ejércitos centroamericanos.

\section{2. ${ }^{\text {a }}$ FASE: RETORNO DEL EJÉRCITO COSTARRICENSE}

Dos días después se produce la llamada Batalla de San Jacinto en la que liberales y conservadores nicaragüenses, juntos, luchan contra el enemigo común que son los filibusteros.

Aun cuando el Dr. Bolaños argumenta que la lejanía y las barreras geográficas demoraron el envío a Nicaragua de los ejércitos centroamericanos, lo cierto del caso es que, desde el mismo mes de mayo, apenas dos meses después de que Costa Rica inició su enfrentamiento con los invasores del territorio nacional, el presidente guatemalteco ordena la movilización de parte de su ejército y pronuncia una proclama de apoyo a esa iniciativa. Por supuesto, aquí está presente la advertencia del mariscal de Saxe. También solicita permiso al gobierno conservador de El Salvador para que las tropas guatemaltecas puedan transitar por ese territorio hasta el puerto de La Libertad, donde se embarcarían a lo largo del golfo de Fonseca, hasta llegar a tierras nicaragüenses.

\section{3. ${ }^{\text {a }}$ FASE: RETORNO DEL EJÉRCITO A COSTA RICA (ABRIL-MAYO 1856)}

Finalizada la Segunda Batalla de Rivas e iniciado el retiro de las fuerzas filibusteras, empiezan a aparecer los primeros casos de los afectados por la epidemia del cholera morbus. Por supuesto que esto planteó en las filas costarricenses la disyuntiva de mantenerse en la ciudad de Rivas o regresarse al país. La disposición inmediata fue abandonar Rivas y evacuar la ciudad poco después de efectuada la batalla.

Llegados a la ciudad de Liberia, Guanacaste, se da de baja al Ejército Expedicionario. Muchos ex soldados, desesperados corren a sus hogares, en el Valle Central costarricense $y$, sin saber que ellos mismos son portadores de esta peste, expanden la enfermedad en la población civil. Obviamente, la tragedia del cholera morbus se extiende. Como afirma Jeffrey (1908):

Un día pasó por las avanzadas un Enemigo [sic] que no fue interpelado por el vigilante centinela. La patrulla que debía gritar ¿quién vive? cayó muerta al golpe de una mano silenciosa. El soldado en la mesa de monte, el oficial en su hamaca, el satélite del ejército en los barrios bajos y el oficial del estado mayor en 
palacio, todos jóvenes y viejos, sin distinción de jerarquías, sucumbieron ante el temido adversario. El cólera, ese azote más terrible que una legión de filibusteros, había penetrado en Rivas (p. 91).

Quizá esta descripción que nos hace el escritor filibustero, nos ayude a comprender la magnitud del problema. El caso es que el cholera morbus diezmó la población costarricense y se constituyó en uno de los problemas de salud, más difícil de solucionar.

\section{ETAPA: SEGUNDA CAMPAÑA (NOVIEMBRE 1856-MAYO 1857)}

Esta etapa es la más significativa y decisiva en toda la guerra librada por los centroamericanos contra el invasor filibustero. Aunque esta etapa se extiende hasta la conclusión de la guerra, para efectos de la periodización, esta cuarta etapa se suele subdividir en cinco sub etapas o fases, cada una con sus propias características.

\section{$1^{\text {a }}$ FASE: CAMPAÑA DEL TRÁNSITO}

Por la cercanía fronteriza y por la claridad conceptual que tenía Juan Rafael Mora en esta guerra, siempre tuvo presente que era fundamental ejercer el control de la vía del Tránsito. Mientras esto no ocurriera, no se iba a liquidar el filibusterismo dado que era por esa vía que constantemente recibía refuerzos y alimentos procedentes de los Estados Unidos. Sin duda esta fue la acción más notable, importante y decisiva de toda esta etapa. Hay que considerar que el Ejército costarricense estaba integrado por gente del Valle Central, desconocedora de la vía de comunicación que se tenía con el río San Juan y otros ríos caudalosos que por su magnitud, sobrepasaban las aguas de los ríos que regaban el Valle Central. De ahí que, además de enfrentar un paisaje agreste, el costarricense era poco versado para enfrentar la acción fluvial que se avecinaba.

En este punto existe una diferencia de criterio entre la tradición historiográfica estadounidense y la tradición historiográfica costarricense; esta se fundamenta de otra manera. Mientras la primera atribuye la grandeza de la acción a Sylvanus Spencer, la tradición costarricense se inclina en reconocer el mérito del mayor Máximo Blanco, jefe de la avanzada del Ejército costarricense que, con 200 hombres a su cargo, ejecutó la acción más audaz, difícil y heroica para controlar la vía del Tránsito. Blanco, con sus hombres, no solo capturó los vapores que se hallaban surtos en los puertos filibusteros, sino que también se encargó de ocupar los sitios y fortalezas que se hallaban en esta vía. Así, la primera acción fue capturar sorpresivamente el sitio de La Trinidad, donde los filibusteros controlaban todo el acceso de Europa hacia Costa Rica y viceversa. Efectuada con éxito esta acción militar, los costarricenses continuaron hasta el puerto de San Juan del Norte. Allí se hallaban surtos también los vaporcitos que prestaban servicios en la vía del Tránsito: el Wheeler, el Machuca, el Morgan y el Bulwer. Capturados estos vapores, con ellos se regresaron, aunque tuvieron que dejar averiados dos de ellos (Wheeler y Machuca) poco antes de Ilegar a La Trinidad. Seguidamente, continuaron hasta el Castillo Viejo donde capturaron el Scott y el Ogden, además de tomar la fortaleza del Castillo Viejo. Más tarde capturaron también el vapor La Virgen. Toda esta acción, comandada por el mayor Blanco fue sumamente rápida, al punto de que cuando el general don José Joaquín Mora (quien había salido quince días después de Blanco), lo único que le quedó por capturar fue una lancha y el puesto de San Carlos (Nicaragua), punto de nacimiento del río San Juan, lo cual obviamente también fue capturado con éxito.

En todo este proceso, el papel asumido por Sylvanus Spencer fue muy importante, dado que dominaba bien las señales y el lenguaje utilizado por los navegantes del Tránsito; sin embargo su gran limitación fue el desconocimiento de la lengua española, lo que le impedía comunicarse de manera fluida con el Ejército. Desde luego que Spencer tiene un mérito pero no el que se le ha concedido dada la limitación que tenía para comunicarse en la lengua nativa.

Cuando el mayor Blanco llegó hasta la desembocadura del río San Carlos en el San Juan, asumió el mando que hasta entonces había compartido con el veterano de la Guerra de Crimea, Pierre Barillier, y tomó todas las direcciones de ocupación de los sitios y de las embarcaciones que navegaban la vía del Tránsito. Esta fue una acción que se tomó con rapidez y que, cuando el general Mora llegó a ese lugar con el grueso del ejército costarricense, poco había que hacer, puesto que ya Blanco había hecho la gran tarea de ocupación y control de dicha vía, determinante para provocar la rendición y caída de los filibusteros.

\section{FASE 1: LA CAMPAÑA DEL TRÁNSITO (DICIEMBRE 1856-MARZO 1857)}

Para Rafael Obregón Loría, basado en lo que sustentan el historiador nicaragüense José Dolores Gámez y el historiador estadounidense David I. Folkman, quien le 
aconsejó a Mora cambiar de posición, Obregón menciona:

Fue Vanderbildt quien le sugirió al presidente de Costa Rica cambiar su política de guerra a muerte contra los filibusteros, y ofrecer en cambio pasaje gratis a los Estados Unidos a todos aquellos reclutas de Walker que desertaran de sus filas (1992, pp. 252-253).

Cuando el general don José Joaquín Mora (quien había salido 15 días después de la avanzada del Ejército) llegó a la desembocadura del río San Carlos, prácticamente toda la vía del Tránsito había sido tomada. Lo único que quedaba por capturar era el más grande de los vapores, por lo general destacado en el lago de $\mathrm{Ni}$ caragua, el San Carlos. Mediante una hábil maniobra dirigida por el general Mora, también fue capturado, con lo que toda la vía del Tránsito quedó en manos del Ejército costarricense.

\section{UNA TRÁGICA BATALLA NAVAL (23 DE NOVIEMBRE DE 1856)}

Este fue el único combate en el mar librado contra los filibusteros, tripulantes de la goleta Granada, comandada por Irving Fayssoux; tuvo, un final trágico para las fuerzas aliadas centroamericanas puesto que el bergantín costarricense Once de Abril explotó en el fragor del combate y también dio lugar a una gran confusión en la mente de Walker quien destaca en su libro La guerra de Nicaragua (p. 400) que un artillero italiano al servicio del ejército costarricense (sin mencionar su nombre) pero que después se le crea una gran confusión al relacionarlo con Federico Maheigt, quien había sido designado de segundo jefe (después de Antonio Valle Riestra) en el mencionado bergantín, con otro artillero, también italiano, que estaba al servicio de las fuerzas expedicionarias costarricenses. En efecto, Federico Maheigt o Macheit, a quien se le atribuía la nacionalidad italiana, estaba al servicio de las fuerzas costarricenses al menos desde 1850 (o antes) y fue una de las personas rescatadas por orden de Fayssoux, quien tenía a su cargo la goleta filibustera Granada. Esta es la razón primordial por la que no puede ser confundido con el italiano al que hace mención Walker y que, suponemos, se trataba de la figura garibaldina de Giovanni Battista Culiolo, mejor conocido como il maggiore Leggero quien parece que sí apareció en las filas costarricenses en el segundo semestre de 1855.

El general José $M^{a}$ Cañas le propone a Walker un "canje de prisioneros" entre los cuales incluía el nom- bre de Federico Maheigt. A esto respondió Walker parcamente en cuanto a Maheigt, me temo que no es posible. ¿Estaría muerto para entonces Maheigt?, puesto que nunca regresó al país. Solamente Walker con su respuesta podría saberlo. Lo que definitivamente no puede ser posible es que este italiano sea confundido con il maggiore Leggero quien luchó al lado de los costarricenses de manera destacada en 1856-1857 y, en una de las acciones inclusive perdió el brazo derecho. Sobre la participación de il maggiore Leggero en esta guerra, la documentación no es abundante ni en el Archivo Nacional como en otros documentos históricos, aunque se dispone de la información necesaria para constatar su intervención en la guerra filibustera.

Esta etapa se lleva a cabo fuera del ámbito de la guerra civil. Esto quiere decir que se produce una "centroamericanización" del conflicto: el problema de la presencia de los filibusteros alcanza una dimensión centroamericana y no particularmente nicaragüense.

Superada la crisis interna del país, Costa Rica decide reincorporarse a la lucha contra los filibusteros, lo cual hace con la orden girada al general José $\mathrm{M}^{\mathrm{a}}$ Cañas para que ocupe San Juan del Sur, el 2 de noviembre de 1856. Sin embargo, en Puntarenas se hacen preparativos de acondicionamiento del bergantín de guerra Once de Abril a fin de enviarlo a ese lugar con hombres y alimentos que refuercen la posición del contingente encabezado por el general don José Joaquín Mora.

Dentro de la perspectiva historiográfica costarricense, la Segunda Campaña es la más decisiva de toda la lucha contra los filibusteros. Con la presencia de las fuerzas expedicionarias centroamericanas, la firma del Tratado de Paz que ponía fin a la guerra civil nicaragüense y la reincorporación de Costa Rica a la guerra, el conflicto se "centroamericaniza". Esta etapa está conformada por tres fases o sub etapas.

\section{1. ${ }^{\text {a }}$ FASE: MOVILIZACIÓN DE LAS FUERZAS CENTROAMERICANAS}

Aun cuando fue en el mes de mayo de 1856 que Carrera tomó la iniciativa de enviar las fuerzas militares a Nicaragua, secundado por El Salvador, la llegada de estos ejércitos se da en el mes de julio. Honduras es el país cuyo envío lo hace en forma más tardía, llegando las primeras fuerzas al mando del general Florencio Xatruch en diciembre, cuando ya Costa Rica se había reincorporado a la guerra filibustera. Tanto las fuerzas guatemaltecas como las salvadoreñas pusieron en evidencia la necesidad de contar con un coordinador militar de 
los ejércitos centroamericanos. Esta designación recayó primeramente en el general Ramón Belloso, del ejército salvadoreño, pero con esta decisión continuaron los males e inconvenientes por cuanto le faltó autoridad, razón que determinó que rápidamente abandonara el escenario de guerra y retornara a su país. En su lugar fue designado el hondureño Xatruch quien también enfrentó sus problemas y limitaciones que impedían una auténtica coordinación militar. Por recomendación de Rafael Carrera, se escogió al general José Joaquín Mora quien ya había participado en la Primera Campaña librada por los costarricenses.

Una vez que el conflicto se centroamericaniza, se produce la llamada Batalla de San Jacinto, única ocasión en que los nicaragüenses, liberales y conservadores juntos, se enfrentan plenamente contra los filibusteros. Más tarde, participarán con los aliados centroamericanos pero no de manera independiente. $\mathrm{Al}$ respecto, dice Bolaños (1995):

Los dos combates en San Jacinto, considerados como una sola batalla en dos etapas, son los únicos en la Guerra Nacional en que nicaragüenses y norteamericanos "estadounidenses" se enfrentan sin auxiliares y queda en una resonante victoria de los nicas. Es por ello que ha pasado a ser el evento más memorable en la historia patria nicaragüense, y siempre se revive la orden espartana de Estrada José Dolores "Firmes hasta caer el último". Andrés Castro, quien mata a un norteamericano "estadounidense" de una pedrada al faltarle fuego a su carabina, se inmortaliza como símbolo espléndido de la lucha desigual de los patriotas de cotona, caites, cutachas y fusil de chispa, y los invasores del destino manifiesto con sus rifles Mississippi, Minié y revólveres Colt. San Jacinto ocurre en el momento oportuno: infunde a los nicaragüenses y a sus aliados centroamericanos renovada confianza en su habilidad de derrotar a los filibusteros precisamente cuando el Ejército Aliado por fin se presta para iniciar la ofensiva contra Walker.

Cuando los ejércitos centroamericanos Ilegan a Nicaragua, lugar donde estaba focalizado el conflicto, la guerra contra los filibusteros alcanza una nueva dimensión: se convierte en una Guerra Nacional Centroamericana, es decir, el conflicto alcanza dimensiones ístmicas: todos los países del área hacen suyo el problema, inclusive en Nicaragua deponen las armas para luchar contra el enemigo común que es el filibusteris- mo. Precisamente, poco después de firmado el tratado en el que conservadores y liberales deponen las armas en Nicaragua, se efectúa la batalla de San Jacinto que es el encuentro bélico donde los nicaragüenses luchan contra los filibusteros como un solo pueblo. San Jacinto hoy día está constituido en una efeméride donde los nicaragüenses, unidos, celebran esta fecha patria. Es el equivalente en Costa Rica al 20 de marzo u 11 de abril.

FASE 3: SITIO DE RIVAS Y RENDICIÓN DE LAS FUERZAS FILIBUSTERAS (MARZO-MAYO 1857)

Con la Campaña del Tránsito y las acciones finales en tierra, se observa con mayor claridad, una estrategia militar acertada. Como lo había señalado Don Juan Rafael Mora desde un principio.

Existe una diferencia conceptual entre la tradición historiográfica costarricense y la posición que asume Bolaños (1995), referente a los momentos históricos de Rivas. Mientras que en el caso costarricense, pasada la Segunda Batalla de Rivas hasta el momento de la rendición de Walker, constituye un solo período en que Rivas es sitiada, en el caso del Dr. Bolaños se mencionan algunos encuentros bélicos o batallas, particularmente la del 23 de marzo de 1857. Esto da lugar a que se pueda destacar mejor la participación del artillero garibaldino il maggiore Leggero, como se le conocía, un enigma hasta ahora ignorado por la historiografía del filibusterismo.

Ante la situación precaria que presentaban en este lapso Walker y sus filibusteros, el comandante Davis "un racista hasta la médula" según palabras de Geyer, este tomó la iniciativa con el fin de procurar una rendición y salida decorosa de los filibusteros en Nicaragua. El comandante Davis previamente solicitó permiso para visitar los campamentos, tanto de los centroamericanos como del filibustero, y así plantear su propuesta de rendición, que fue firmada el $1^{\circ}$ de mayo de 1857 . Por los acontecimientos que siguieron, vale señalar que la rendición se produjo ante el comandante Davis y no ante las autoridades del Ejército Aliado Centroamericano. La única explicación que existe por esta anomalía y el error cometido, es el deseo de terminar lo antes posible con el peligro filibustero en Centro América.

Una de las características fundamentales de esta guerra fue sitiar las principales ciudades y con ello minar toda posibilidad de resistencia de la ciudad sometida. Rivas no fue la excepción. Es aquí donde existe una diferencia entre la historiografía nicaragüense y la costarricense. Mientras en la segunda existe toda 
una periodización e, incluso, se habla de la Primera Campaña y de la Segunda Campaña que es la que determina el escalonamiento de un conflicto local a uno regional, en el caso costarricense se habla del sitio de Rivas, el cual se va a extender hasta la rendición misma del filibustero; en el caso del Dr. Bolaños particularmente, habla de que los momentos históricos de Rivas son cinco, por cuanto menciona dos de los encuentros bélicos que se dan en el Ilamado "sitio" de la ciudad rivense. Precisamente, en uno de estos enfrentamientos (batalla del 23 de marzo de 1857) es donde destaca el soldado italiano maggiore Leggero.

El 3 de diciembre de 1856 sale de San José la vanguardia del ejército, integrada por 200 hombres al mando del mayor Máximo Blanco y del veterano de la Guerra de Crimea, Pedro Barillier. Aunque aparentemente la jefatura del mando era compartida al iniciarse la expedición, lo cierto del caso es que al llegar a la desembocadura del río San Carlos en el río San Juan, es el mayor Blanco quien dirige todas las acciones a lo largo del río fronterizo hasta el puerto de San Juan del Norte (junto con las aguas del lago de Nicaragua y el istmo de Brito, es lo que se conoce como la vía del Tránsito).

Como rasgo especial de esta fase es necesario indicar que de ella se cuenta con crónicas o diarios preparados por los mismos participantes en estos hechos históricos que, utilizados racionalmente y cotejados con las fuentes históricas, constituyen una importante contribución a la memoria histórica de estos hechos.

La vía del Tránsito era la fuente permanente por donde se alimentaba el filibusterismo: hombres, bastimentos, recursos financieros, por lo tanto, como decía Don Juan Rafael Mora, sin su ocupación y control era casi imposible de derrotar a Walker y sus filibusteros, pues la vía del Tránsito era la arteria principal del filibusterismo.

Por otro lado, el Ejército Expedicionario costarricense estaba conformado fundamentalmente por gente del Valle Central que desconocía la zona del Tránsito. Al corresponderle al país enteramente tomar posesión de esta vía, transforma en hazaña lo realizado.

En cuanto a Spencer, hay una divergencia de criterio entre la historiografía estadounidense y la costarricense. Mientras aquella afirma que toda la Campaña del Tránsito transcurrió bajo la dirección de Spencer, ésta destaca la avanzada del Ejército Expedicionario costarricense, bajo las órdenes del mayor Blanco y, luego, el general don José Joaquín Mora.

\section{ETAPA: INTENTOS POSTERIORES DE WALKER}

Es doloroso reconocer que en la rendición del $1^{\circ}$ de mayo de 1857 no se impuso a Walker obligación alguna de no regresar a Centroamérica. Todo lo contrario, a la hora de rendirse ante el comandante Davis, lo hizo con la convicción plena de que era el presidente legítimo de Nicaragua y que esto le daba derecho, desde luego, a retornar posteriormente en procura del poder que había dejado. Además de la llegada del Vesta en 1855, hay que señalar que fueron tres los intentos de invasión a Nicaragua. En efecto, después de haber firmado su rendición ante el comandante Davis, efectúa tres intentos más.

\section{1. ${ }^{a}$ FASE: INVASIÓN DEL FASHION (23 NOVIEMBRE 1857)}

Apenas había transcurrido poco menos de un año, cuando Walker hace su primer intento. Al llegar a Punta Castilla, desembarca algunos de sus hombres y continúa viaje hasta San Juan del Norte. Ahí ordena a Anderson capturar los vapores de la vía del Tránsito y luego se estaciona en la boca del río Colorado (aunque los límites no estaban definidos, es conveniente decir que este fue el lugar costarricense donde el filibustero estuvo). No obstante, es obligado a rendirse por el comodoro Hiram Paulding quien lo lleva de regreso hasta Nueva York.

\section{2. ${ }^{a}$ FASE: SUSAN (8 DICIEMBRE 1858)}

El otro intento de invasión que Walker que lleva a efecto, aunque en él no participa, es el que se efectúa con la goleta Susan. Al igual que en el caso anterior, también fracasa al naufragar esta embarcación en el arrecife Glover, frente a las costas de Belice, el 16 de diciembre de 1858.

Como resultado del naufragio, los filibusteros son rescatados por un buque de la marina británica y conducidos a Mobile, Estados Unidos.

\section{3. ${ }^{a}$ FASE: TRUJILLO, HONDURAS, 6 DE AGOSTO 1860}

Al presentarse grandes dificultades para la invasión de Nicaragua por la vía normal de San Juan del Norte, Walker tiene la idea de llevar a cabo la invasión por el puerto de Trujillo, Honduras. Con el fin de burlar las leyes de neutralidad, decide abordar barcos fruteros que le permiten hacer este acto. Así, el 6 de agosto de 1860 
toma por sorpresa el puerto de Trujillo y toma disposiciones para invadir la isla de Roatán, para luego continuar hacia Nicaragua en procura del poder perdido. Aunque sorpresivamente tiene éxito en la toma de TrujiIlo, no cuenta con que ahí se encuentran los británicos y, después de una intensa persecución, llega a rendirse ante el Icarus, de la flota naval de S. M. Británica. Como resultado de esta rendición, los británicos, a diferencia de los estadounidenses, entregan a las autoridades hondureñas al prisionero.

\section{ETAPA: EL EPÍLOGO}

Como una ironía de la historia, los principales protagonistas de estos hechos, acaban sus días de existencia en el mes de setiembre de 1860. Con menos de veinte días, ambos son ejecutados, por las autoridades hondureñas el primero y por autoridades costarricenses el segundo. Obviamente, las razones que se tuvieron son muy diferentes para juzgarlos y sentenciarlos a ser pasados por las armas.

\section{1. ${ }^{\text {a }}$ FASE: MUERTE DE WALKER, 12 DE SETIEMBRE DE 1860 (TRUJILLO, HONDURAS)}

El acostumbrado intento de Walker por rendirse ante autoridades estadounidenses, esta vez no le resultó y tuvo que rendirse ante autoridades inglesas quienes, de inmediato, lo entregaron a las autoridades hondureñas. Estas le hicieron un juicio y terminaron por sentenciarlo a morir fusilado. Con su ejecución finaliza el empecinamiento filibustero en Centroamérica.

\section{2. ${ }^{\text {a }}$ FASE: MUERTE DE JUAN RAFAEL MORA, 30 DE SETIEMBRE DE 1860 (PUNTARENAS)}

En el mismo mes de setiembre, con apenas 18 días de diferencia, Don Juan Rafael Mora es sentenciado a morir fusilado, después de intentar retomar el poder en Costa Rica. También fracasa en un intento de recuperación del poder, luego de ser sentenciado por un cuestionado Consejo de Guerra, es condenado a morir pasado por las armas.

Con la desaparición física de estos dos personajes históricos termina el difícil reto que enfrentaron las repúblicas centroamericanas y que amenazaba seriamente la conservación de la nacionalidad centroamericana.

Con esto se puso fin al enfrentamiento de dos adversarios irreconciliables en uno de los capítulos más tene- brosos de la historiografía republicana de Centroamérica que el filibusterismo decimonónico atentaba acabar con la identidad histórica de las repúblicas centroamericanas, poniendo fin a los afanes expansionistas del Destino Manifiesto estadounidense. Con esto termina esta pesadilla histórica centroamericana.

\section{REFERENCIAS BIBLIOGRÁFICAS}

Araya, M. (2006). Relaciones Internacionales y lucha contra los filibusteros. San José: Comisión Nacional de Conmemoraciones Históricas.

Bolaños. A. (1995). William Walker: el Predestinado de los Ojos Grises, IV: La Guerra Nacional, St. Charles, Missouri. San José: impresión privada.

Bouthoul. G. (1971). La Guerra. Barcelona: Oikos Tau ediciones.

Comisión Nacional de Conmemoraciones Históricas. Mentor Costarricense 1842-1846 (pp. 43-44). San José: Oficina de Publicaciones, Universidad de Costa Rica.

Costa Rica Oficial. (1860). Exposición de los motivos del cambio político, acaecido en Costa Rica el 14 de agosto de 1859 (8). San José: Imprenta Nacional.

Durán, Luzio J. (2010). Juan Rafael Mora Porras: escritos selectos. San José: Imprenta Lara Segura.

Hobsbawm. E. (2003). Años Interesantes. Una vida en el siglo XX. Barcelona: Crítica.

Jeffrey. J. (1908). Historia de los filibusteros (pp. 91). San José: Imprenta Nacional.

Jiménez. J. \& Víquez. F. (1914). Relativos a la Guerra Nacional de 1856 y 57 con sus antecedentes. San José: Tipografía Nacional.

Korte, W. (2010). Los Diarios de la Campaña del Tránsito y la otra cara de la moneda. Conferencia presentada en el simposio sobre "Filibusterismo y Destino Manifiesto" realizado del 2-4 mayo 2007 en la sede de Liberia de la Universidad de Costa Rica, 239-256.

Montúfar, L. (1887). Walker en Centroamérica. Documento descargado de http://archive.org/stream/walkerencentroa00montgoog/walkerencentroa00montgoog_djvu.txt

Obregón. R. (1992). Costa Rica y la guerra contra los filibusteros. Alajuela: Museo Histórico Cultural Juan Santamaría.

Ortega. J. \& Medina. (1972). Destino Manifiesto. Sus razones históricas y su raíz teológica. México: Secretaría de Educación Pública. 
Juan Rafael Mora y la Campaña Nacional

Pérez. J. (1928). Obras históricas completas del licenciado Jerónimo Pérez, impresas por disposición del Excelentísimo Sr. Presidente de la República don Adolfo Díaz, bajo la dirección y con notas del doctor Pedro Joaquín Chamorro. Managua, Nicaragua: Imprenta y Encuadernación Nacional.

Picado. T. (1922). Antecedentes de la Guerra Nacional. Apuntes para nuestra historia diplomática. San José: Editorial Alsina.

Rousseau. J.J. (1959). El Emilio o la educación. México: Editorial Novaro.

Schaft A. (1974). Historia y verdad. México.: Editorial Grijalbo.

Soley, T. (1947). Historia Económica y Hacendaria de Costa Rica. San José, Costa Rica.: Editorial Universitaria.

Vargas. A. (2013). El lado oculto del Presidente Mora: Costa Rica versus el expansionismo de Estados Unidos. San José: Editorial Eduvisión. 